\title{
Etunimien ajankuva
}

Minna Saarelma-Paukkala: Etunimikirja. Suomalaiset nimitrendit 2000-luvulla. Kirjokansi 135. Helsinki: Suomalaisen Kirjallisuuden Seura 2017. 268 s.

ISBN 978-952-222-831-14

Minna Saarelma-Paukkalan tuore Etunimikirja on sujuvasti kirjoitettu yleiskatsaus Suomen nykyiseen etunimikäytäntöön ja, osin, nimenvalinnan opaskin. Kyseessä ei siis ole perinteinen sanakirjamainen etunimikirja.

Alaotsikko Suomalaiset nimitrendit 20oo-luvulla on kirjan pääteema. Kansainvälistyminen ja individualismi on yleensäkin nähty länsimaissa nimivarannon kasvun syynä, ja näihin puoliin myös Saarelma-Paukkalan teos painottuu.

Teos jakautuu kahdeksaan lukuun. Aluksi luodaan lyhyt katsaus maamme etunimihistoriaan. Luku 2 käsittelee 1900luvun etunimistöä, luku 3 kirjan tarkentavan otsikon mukaisia suomalaisia 2000luvun nimitrendejä ja luku 4 Suomen vähemmistöryhmien 200o-luvun etunimistöä ja monikulttuuristen perheiden nimenvalintaa. Sen jälkeen sijansa saavat lapsen etunimen valinta (luku 5) sekä suomalainen nimipäiväkulttuuri ja nimipäiväkalenterit - kissoja, koiria ja hevosia myöten (luku 6). Luvussa 7 käsitellään eurooppalaisia ja amerikkalaisia nimitrendejä ja luetellaan maittain suosikkinimiä. Luku 8 "Etunimet muualla kielessä" käsittelee hypokoristisia etunimiä eli etunimeen perustuvia hellittelynomaisia lyhentymiä tai johdoksia, etunimiä suku- ja paikannimissä, kaupallisissa nimissä sekä etunimiä sisältäviä sananparsia ja sutkauksia. Loppuun on sijoitettu tuoreet nimipäiväluettelot: suomalaiset ja suomenruotsalaiset nimipäivät sekä ortodoksiset ja saamelaiset nimipäivät.
Teoksessa tarkastellaan koko väestön etunimiä rajaamatta kohdetta ennalta nimien tai nimenkantajien kielen tai muun taustan mukaan. Tämä on ehdoton plussa, ellei jopa välttämättömyys, sillä paikan- ja sukunimistöömme verrattuna etunimistö on vähiten kielisidonnaista. Etunimet ovat kerrallisia, yhden ihmisiän mittaisia, jos sitäkään. Etunimiä ja nimitrendejä on koko historiamme ajan omaksuttu muualta.

Tällainen katsaus on tarpeellinen myös siksi, että etenkin 1970-luvulta lähtien Suomen etunimistö on saanut entistä enemmän sekä vaikutteita että suoraa nimilisää muista kulttuureista. Sen on huomannut myös lehdistö, jonka kestotavaraa ovat artikkelit suosituimmista etunimistä, etunimien jakautumisesta alueittain sekä viranomaisten hylkäämistä ja hyväksymistä etunimistä. Lehdistö tuottaa sujuvasti avoimen datan avulla tilastoja (ks. esim. sivut 71-75) ja kyselyitä etunimistä ja niiden käytöstä, ja asiantuntijoilla on kunnia niitä kiireessä kommentoida.

Tapahtunut nimiympäristön ja arvojen muutos on otettu huomioon myös uudessa, joulukuussa 2017 vahvistetussa etu- ja sukunimilaissa (2017/946), joka astuu voimaan 1.1.2019. Uutta on muun muassa se, että nykylain edellyttämää kotimaisen nimikäytännön mukaisuutta on laajennettu etunimistön osalta kattamaan kaikki väestötietojärjestelmään kirjatut etunimet kielestä riippumatta. Kirjan ajoitus herättääkin kysymyksen, miksi se haluttiin julkaista jo alkusyksystä 2017. Miksi ei maltettu odottaa uuden etu- ja sukunimilain valmistumista? Nyt teoksessa kerrataan pian vanhentuvan nimilain edellytyksiä (s. 131-136), kun olisi voitu tuoreeltaan esitellä ne muutokset, jotka edustavat paremmin nykyistä nimi- 
käytäntöä kuin käytöstä poistuva laki. Aika tiukka tulkinta nykylaistakin on, että vain islaminuskoon kääntynyt suomalainen voisi antaa lapselleen jonkin islamilaiseen kulttuuriin kuuluvan nimen, kuten Fatima ja Omar (s. 133). Jo Suomen Sukututkimusseuran HisKi-tietokannasta selviää, että näitä nimiä on ollut muillakin suomalaisilla $1800-l u v u l t a$ alkaen.

\section{Historiakatsaukset}

Kirjan kaksi ensimmäistä lukua kertaavat etunimistömme historiaa tiivistetysti aiemmin julkaistun pohjalta (lähinnä Blomqvist 1993; Kiviniemi 1982, 2006). Sinänsä hyödylliset taustoitukset olisi voinut viitteistää tarkemmin, sillä aina ei selviä, mikä tieto tai käsitys on keneltäkin peräisin. Lisäksi ne olisi voinut ajantasaistaa tuoreemman lähdeaineiston ja tutkimustiedon avulla.

Kalenterien vaiheet esitellään hyvin, mutta toteutuneen nimikäytännön esittely esimerkiksi sellaisten viime vuosikymmenten julkaisujen ja opinnäytetöiden avulla, joissa on käsitelty erilaisia, asiakirjoista todennettuja nimikäytäntöjä, on jäänyt Arjavan (2005) kangasniemeläisten nimenantoa käsittelevän tutkimuksen varaan. 1700- ja 1800-luvun kannalta hyödyksi olisivat olleet esimerkiksi Borgin (1995), Kotilaisen (2008), Lampisen (1997), Lappalaisen (1996), Oksasen (2007), Paikkalan (2006), Rajasuun (2013), Tokolan (1997) ja Turusen (1996) työt.

Sujuva kirjoittaminen näyttää teoksessa monin paikoin vetäneen mutkia suoriksi. Etunimissä yksinimisyydestä kaksinimisyyteen siirtymisen todetaan omaksutun Itä-Suomessa hitaasti, "koska yksinimisyyttä tuki siellä ortodoksinen nimenantoperinne, jonka mukaan lapselle annetaan vain yksi nimi” (s. 27). ItäSuomesta suurin osa ei ole ollut ortodoksisen kirkon vaikutusaluetta 1300-luvun jälkeen. Yksinimisyyttä on Itä-Suomessa säilyttänyt paljolti asenne, jonka mukaan useampinimisyyttä on pidetty herraskaisena koreiluna - ja aikalaiskirjoituksen mukaan jopa vanhojen kastekirjojen ahdas viivaväli sai papit suosimaan yksinimisyyttä (Paikkala 2006: 337).

Moniin nyt itsestäänselvyyksinä toistettuihin asioihin olisi löytynyt tarkennusta jo julkisista verkkotietokannoista. Esimerkiksi väite yhdysnimien ilmaantumisesta kirkonkirjoihin vasta 1800 -luvun lopulla (s. 40) kumoutuu jo pelkästään hakemalla HisKi-tietokannan kastettujen luettelosta nimiä Annastina ja Majalisa, joista on merkintöjä 170o-luvulta lähtien. Erikseenkin yhdysnimiä on kirjoitettu; yhdysmerkki vakiintui suomen kieleen vasta oikeinkirjoituksen vakiintumisen myötä (esim. Kolehmainen 2014: 257).

Nimien ottaminen almanakkaan ei todista sitä, milloin kyseiset nimet on omaksuttu kansan käyttöön, mutta voi toki tätä prosessia vahvistaa ja vakiinnuttaa. Tästä sopii esimerkiksi Venäjän hallitsijaperheen nimien lisääminen almanakkaan. Tätä kommentoitaessa (s. 25) olisi voinut mainita, että esimerkiksi Aleksanteri oli yleisessä käytössä jo ennen autonomian aikaa. Toisaalta Oskari tuli käyttöön Ruotsin kruununprinssinä ja kuninkaana (vuodesta 1844) olleen Oskar I:n aikana, jolloin Suomi ei ollut enää osa Ruotsia. Almanakkaan nimi ilmestyi vasta 1900luvulla.

Etymologisista etunimikirjoista teoksessa ovat mukana keskeiset kotimaiset, mutta muualla julkaistuja eturivin nimistöntutkijoiden teoksia ei juuri huomioida. Kun suomalaiset etunimikirjat ovat Kustaa Vilkunan ja Pentti Lempiäisen jälkeen pitkälti toisintoja edeltäjistään, nimien selityksetkin ovat siirtyneet sellaisinaan eteenpäin. Esimerkiksi Elviran ja Eleanooran todetaan tulleen arabialaisesta nimimaailmasta ja Ellinooran persiasta (s. 34, 118), vaikka nämä tulkinnat on kiistetty (ks. mm. Seibicke 1996; Kohlheim \& Kohlheim 2013). 
Nimenantoperusteita käsitellessään tekijä kertoo suvun mukaan nimeämisen olleen varsin suoraviivaista (s. 138). Tässä olisi voinut ottaa mukaan tuoreempaa tutkimusta. Huomiotta ovat jääneet ne tutkimukset, joissa annetaan asiasta monisyisempi kuva (esim. Järvinen 2001; Kotilainen 2008; Oksanen 2007).

\section{Eri nimet ja nimenkantajat}

Saarelma-Paukkalan teosta edeltäneet, lähteinä käytetyt Kiviniemen teokset keskittyivät tarkastelemaan etunimistöämme äidinkieleltään suomenkielisten näkökulmasta. Tämä antoi vaikutelman "suomalaisemmasta" Suomesta kuin mitä todellisuus oli. Se myös vaikeuttaa eri nimien määristä esitettyjen tietojen vertailua eri aikakausien välillä: kun Kiviniemen (2006) laskelmien mukaan suomenkielisellä väestöllä oli 1900-luvulla käytössään noin 50000 erilaista etunimeä, Saarelma-Paukkala kertoo huhtikuussa 2017 eläneillä Suomen kansalaisilla olleen Väestörekisterikeskuksen mukaan 120502 eri etunimeä (s. 89). Nimimäärän kasvu johtuu osin suomalaisten luomista uusista nimistä, osin maahan tulleiden tuomista uusista nimistä sekä siitä, että Kiviniemen luku sisälsi vain suomenkielisten nimet.

Erilaisten nimien määrä on eri asia kuin niiden kantajien määä, ja sen kirjoittaja tuo hyvin esiin. Uniikilla nimellä on vain yksi kantaja ja harvinaisilla nimillä vain muutama. Vaikka uniikkinimiä annetaan enemmän, vuoden 2016 ikäluokan lapsista niiden kantajia oli 4-5 prosenttia (s. 9o). Samantyyppinen huomio koskee Viron nimistöä: vuoden 2016 suosituimmat nimet ovat yllättäen venäläisiä. Tämä johtuu siitä, että Viron venäläisillä on suppeampi nimivaranto kuin vironkielisillä, jolloin venäläisnimet nousevat kärkeen (s. 199).

Kirjoittaja nostaa esiin myös uniikkinimien määrää lisäävän teknisen teki- jän: yhdysmerkin (s. 92). Kun yhdysnimiä muodostetaan tavallisista nimistä mutta niin, että nimiyhdistelmä on uusi, saadaan yksinkertaisella tavalla ainutlaatuinen nimi, esimerkiksi Ronja-Riina ja Neo-Elmeri (s. 93). Jos pelkästään yhdysmerkin ja yhdysmerkittömän yhteenkirjoittamisen avulla luodut nimet poistettaisiin uniikkinimien ryhmästä, joukko hupenisi huomattavasti.

\section{0- ja 2000-luvun nimitrendit}

Luvussa 2 kuvataan 1900-luvun nimitrendit ja suosionvaihtelut pääpiirteissään Kiviniemen $(1982,2006)$ teosten pohjalta. Katsaus perustuu jo reaalisesti toteutuneen nimikäytännön seuraamiseen. "Suomalaisnaisten" ja "suomalaismiesten" yleisimmät ensinimet 1900-luvulta luetellaan vuosikymmenittäin (s. 49-51). Se, perustuvatko luettelot Kiviniemen laatimiin, äidinkieleltään suomenkielisten nimien luetteloihin vai kaikkien suomalaisten nimiin, jää epäselväksi.

Uutta tietoa sisältää kirjan pääteeman mukainen luku 3 eli "200o-luvun nimitrendit". Huomattava tieto on vieraskielisen väestön osuuden kasvu vuoden 1980 noin $0,2 \%$ :sta vuoden 2016 noin $6,5 \%$ :iin. Suurimmat vieraskielisten ryhmät ovat venäläiset ja virolaiset. Vuonna 2017 elossa olleiden miesten ja naisten kärkinimet ovat edelleen samoja tuttuja kuin ennenkin - Tuula ja Ritva, Timo ja Juha -, mikä selittyy suurilla ikäluokilla. Edelleenkin tytöille annetaan enemmän erilaisia nimiä kuin pojille.

Kun mennään 200o-luvulla annettuihin ensinimiin, kärki siirtyy uusvanhoihin nimiin (Aino, Emma, Eetu, Otto) ja kansainvälisiin muotinimiin (Isla, Luca, Noel, Vanessa). Uniikkinimien osuus kasvaa, ja lähes puolet lapsista on saanut kolme nimeä. Etunimiksi annetaan omakielisiä sanoja, jotka ovat myös yleisnimiä (Lumi, Sisu). Julkisuuden henkilöiden mukaan nimeämisessä valokeila 
on siirtynyt kuninkaallisista ja ylempien sosiaaliluokkien edustajista viihdemaailman julkkiksiin (esim. Erin, Minea, Robin). Nimenvalinnassa on alueellisten erojen sijasta enemmän sosioekonomisia eroja (s. 74-77). Perustelematta jää väite siitä, että "maakunnalliset erot olivat suomalaisten nimenannossa vielä 1900-luvun alkupuolella erittäin selviä” (s. 71). Millä tavoilla maan eri osien nimenanto erosi toisistaan?

Uusia nimiä luodaan myös analogian avulla, esimerkkeinä Leenan mallin mukaiset Jeena ja Meena. Kirjoittaja korostaa useassa kohdin (esim. s. 82-83, 94), että tällaiset nimet ovat vain toistensa muunnelmia, jolloin niille on tarpeetonta etsiä kantanimeä tai sisällöllistä merkitystä. Nimiluetteloistaan kirjoittaja silti viisaasti toteaa, että listan nimille voi olla muitakin tulkintoja. Muottinimet ovat saaneet yhä enemmän suosiota, kun vanhemmat hakevat yksilöllisempiä nimiä tai haluavat antaa kaikille lapsilleen toisiaan muistuttavia nimiä. Heimoutta sekin. Aikasidonnaista on, millainen muotti milloinkin on muotia (s. 83).

Kiintoisa on havainto omakielisten nimien sukupuolesta. Vaikka osa vanhemmista pyrkii tietoisesti antamaan lapselleen sukupuolineutraalin nimen, nimillä on silti taipumus sukupuolittua - sekä käytännön nimenannon myötä että kuulijan nimien sisältöön liittämien asenteiden mukaan (s. 98-101).

Luku 7 "Eurooppalaiset ja amerikkalaiset nimitrendit" liittyy tavallaan lukuun 2. Koko Suomen väestön mukaan ottamisen ohella muunkin maailman nimitrendien huomioiminen on SaarelmaPaukkalan teoksen uutuus. Kirjassa esitellään kymmenen tyttöjen ja poikien kärkinimeä 12 maasta. Omat osuutensa saavat Viro, Ruotsi ja Yhdysvallat. Viimeksi mainitun painoarvo onkin melkoinen amerikkalaisen viihdeteollisuuden ansiosta. Samansuuntaiset nimitrendit jylläävät myös muualla, ja samat kärkinimet ran- tautuvat meillekin, hyvänä esimerkkinä Sofia (s. 192). Monikohan nykyvanhempi tulee ajatelleeksi, että moderneiksi ymmärretyt Luka ja Nooa ovat itse asiassa uus- tai vanhatestamentillista perua, raamatullista nimimuotia, jota myös nykypäivän amerikkalaisvanhemmat suosivat (s. 205-207)?

\section{Vähemmistöryhmien nimet}

Luvun 4 ("Suomen vähemmistöryhmien etunimet 200o-luvulla") katsaus on aiempiin kotimaisiin etunimikirjoihin verrattuna uutta ja tarpeen. Väliotsikointi ja aiheen käsittely ei ole kuitenkaan täysin johdonmukaista. Väliin ryhmät on muodostettu nimenkantajien etnisyyden tai uskonnon mukaan, väliin nimenkantajien tai nimen kielen mukaan: on "suomenruotsalaisten", "saamelaisten" nimet, "ortodoksien nimenanto" ja "muslimiväestön etunimet" sekä "viittomakieliset", "venäläiset", "virolaiset" nimet ja "muut vierasperäiset nimet".

Rajanveto erikielisten nimien välillä on toki vaikeaa, mutta olisiko "venäläisten nimien" sijasta voinut käyttää ilmausta "slaavilaiset nimet"? Joukossa näyttää nimittäin olevan myös Ukrainassa, ValkoVenäjällä ja Bulgariassa syntyneiden nimiä. Esimerkkiluetteloon on lipsahtanut myös supisuomalaisilla yleinen Odessa, joka ei ole venäläinen etunimi, mutta kylläkin kaupunki Krimillä. Suomessa se sai etunimenä nostetta 2000-luvun alussa jääkiekkoilija Jari Kurrin ja Vanessa Forsmanin tyttären nimestä, johon äidin nimikin on voinut antaa mallia. Ryhmä "muslimiväestön etunimet" sisältää arabian-, persian-, turkin- ja somalinkielisiä nimiä.

Ortodoksista etunimistöä käsitellessään kirjoittaja toteaa (s. 114), että 1900luvun alun kansallisuusaate "innosti myös ortodokseja suomalaisnimien käyttöön”. Ortodoksien etu- ja sukunimien muuttamista edisti tuolloin voimakas 
suomalaistamispaine, mitä edusti esimerkiksi Iivo Härkösen ehdotus ortodoksisen ristimänimistön suomalaistamiseksi vuonna 1930. ${ }^{1}$ Tuoretta näkökulmaa olisi saanut Iljinin (2013) opinnäytetyöstä, jossa tarkastellaan Helsingin ortodoksisessa seurakunnassa 2000-luvulla annettuja ensinimiä.

Muita vierasperäisiä nimiä käsittelevässä osuudessa olisi ollut tilaisuus selventää muutamien meillä etunimiksi merkittyjen nimien luonnetta omassa kulttuurissaan. Esimerkiksi vietnamilaisissa nimissä naisten nimiin lisätään kirjoitettaessa etu- ja sukunimen väliin 'sukuun kuuluvaa tytärtä' ilmaiseva Thi ja miesten nimissä vastaava 'poikaa' ilmaiseva Van. Omassa kulttuurissaan ne ovat keski- tai välinimiä, eivät etunimiä.

\section{Nimipäiväkulttuuri ja almanakka- uudistukset}

Vuoden 1929 almanakkauudistuksesta todetaan, että kalenterista poistettiin useita germaanis-skandinaavisia nimiä, joista monet siirtyivät suomenruotsalaiseen nimipäiväalmanakkaan (s. 30, 164). Kun nimet heijastavat yhteiskunnan arvojen muuttumista, kalenterien jaon ideologista taustaa olisi voinut avata enemmän. Entä kuinka onnistuneelta nimipäiväkalentereiden kieliperustainen jako näyttää nykyistä etunimivarantoa ja sen jakautumista ajatellen? - Tuolloista uudistusta on pidetty "suomalaisperäisen tai suomalaiseksi leimautuneen nimistön lopullisena voittona" (s. 29). Tosiasia kuitenkin on, että etunimistö oli kirkonkirjoissakin suomalaistunut vuoden 1863 kielireskriptin voimaantulon jälkeen eli viimeistään 1880-luvulla, nimipäiväalmanakoista riippumatta.

1. Ortodoksisen kirkon kansallistamista ja etunimien asemaa on Saarelma-Paukkalan teoksen julkaisemisen jälkeen tarkastellut Patronen (2017: $68,72-73)$
Kirjassa tulee hyvin esiin se, miten nimipäiväkalenterien nimien valinta on muuttunut ajan mittaan ortodoksiseen kalenteriin verrattuna (s. 165, 169, 170, 182). Se, kuinka nimet päätyvät almanakkaan ja miten ne sijoitetaan, on aina arvoja kulttuurisidonnaista.

Nimipäivien vietto todetaan olennaiseksi osaksi suomalaista kulttuuria ja sitä esitellään monen sivun verran. Ohimennen todetaan, että alueellisia eroja on ja läntisessä Suomessa nimipäiviä vietetään innokkaammin kuin Itä-Suomessa. Päiväkodit ja koulut yhtenäistävät kansaa tältä osin, mutta tässä olisi silti kiintoisa selvityksen paikka jatkossa.

\section{Termit ja käsitteet}

Kun teoksessa puhutaan virallisista nimistä, olisi historiakatsauksessa voinut pohtia myös virallisen nimen käsitettä ja nimen kielisyyttä. Monilla kun tuntuu olevan käsitys, että kirkonkirjoissa suomenkielisillekin kirjatut ruotsinkieliset nimiasut ovat olleet arkista käyttötavaraa.

Patronyymeistä olisi voinut antaa tarkemman kuvan. Jää käsitys, että asiakirjoihin etunimen jälkeen kirjatut patronyymit, kuten Matintytär ja Matinpoika, olisivat olleet alun alkaen suomenkin kieleen kuulunut käytäntö (s. 19, 22, 226), vaikka kansanomainen käytäntö osoittaa genetiivisen määritteen jatkuvuutta. Ajatellaanpa vaikka sukunimeä Matinolli, joka oli alkujaan talonnimi, tai saamelaisten perinteistä nimikäytäntöä tyyliin "Maggan Joosepin Elli" (s. 108).

Kirjoittaja on ottanut käyttöön termin ensinimi, jolla hän tarkoittaa ensimmäistä etunimeä, ja termin jälkinimi, jolla hän tarkoittaa ensinimen jälkeen merkittyjä etunimiä. Termit ovat lyhyitä ja käytössä näppäriä. Etenkin jälkinimi on kuitenkin sikäli ongelmallinen, että laajemmassa kontekstissa sen voi ymmärtää lisätai sukunimeksi, joita tarkoittavia termejä 
ovat esimerkiksi ruotsin efternamn ja saksan Nachname.

Luvun 8 "Etunimet muualla kielessä" olisi voinut rajata harkitummin. Etunimistä muodostetut lempinimet toki kuuluvat asiaan; niitähän on otettu viime vuosikymmeninä yhä enemmän virallisiksi nimiksi niin, että niistä on tullut neutraaleja myös kasteniminä. Tuotemerkit, etunimien appellatiivistuminen ja etunimen sisältävät vakiintuneet ilmaukset sopivat myös kategoriaan. Sen sijaan etunimet kadunnimissä ja sukunimissä ovat turhaa teeman venyttämistä alueille, joissa vastausten hakeminen on jo monitahoisempaa. Esimerkiksi kadunnimissä ei monestikaan ole kysymys ensisijaisesti etunimistä vaan henkilöiden muistamisesta, kuten tekijä itsekin toteaa (s. 228229). Eri asia ovat tietoisesti etunimiaihepiirin mukaisesti annetut kadunnimet. Sukunimien selittäminen mekaanisesti, pinnalta näennäisen etunimisisällön mukaan ei ole perusteltua "tiedonjakamista" (s. 224). Yksityiskohdista mainittakoon, että muinaissuomalaiseksi miehennimeksi esitetty Rautia (s. 223) sisältää 'seppää' tarkoittaneen liikanimen.

Lähdeluettelosta ovat unohtuneet Sartjärven (2011, ks. s. 82) opinnäytetyö ja Mikkosen (2002; ks. s. 123) toimittama ulkomaisten henkilönnimien opas. Lukijalle hyödyksi olisi varsinaisiin tekstiosuuksiin sisältyvien nimien hakemisto.

\section{Lopuksi}

Saarelma-Paukkalan teoksen parasta antia on pääteeman mukaisesti nimitrendit, joiden kuvaukset kattavat sekä koko 1900luvun että 2000-luvun alkuvuosikymmenet. Viimeksi mainitulla ajanjaksolla kirjoittaja on selvästi omalla alueellaan, kuten kalenteriosuuksissakin. Uutta ja ilahduttavaa on ajanmukaisuus: kirjan perussävynä on koko väestön huomioonottaminen sekä kansainvälisyyden mukaan tuominen muiden maiden nimi- trendejä verraten. Näyttää siltä, että maailman nimitrendit ovat yhtenäistymässä.

Sirkka Paikkala

etunimi.sukunimi@kotus.fi

Kirjoittaja on dosentti Helsingin ja Turun yliopistoissa sekä erityisasiantuntija Kotimaisten kielten keskuksessa.

\section{Lähteet}

Arjava, Hellevi 2005: Alpiini ja Otteljaana. Kangasniemeläisten etunimet 1864-1899. Suomi 19o. Helsinki: Suomalaisen Kirjallisuuden Seura.

Blomqvist, Marianne 1993: Personnamnsboken. Helsinki: Finn Lectura.

BorG, KaJ 1995: Dopnamn och namngiving $i$ Gamlakarleby 1657-1928. Pohjoismaisten kielten lisensiaatin tutkielma. Åbo Akademi.

Etu- ja sukunimilaki 2017/946. https://www. finlex.fi/fi/laki/alkup/2017/20170946 (19.12.2017).

HisKi $=$ Historiakirjojen (kastettujen, vihittyjen, muuttaneiden ja haudattujen luetteloiden) hakuohjelma. Suomen Sukututkimusseura. http://www.genealogia.fi/hiski (1.1.2018).

HÄRKÖNEN, IIvo 1930: Karjalaisten nimiopas. Karjalan Sivistysseuran julkaisema opasvihkonen karjalaisten uusien kansallisten suku- ja ristimänimien valintaa varten. Helsinki: Karjalan Sivistysseura.

Iljin, Outi 2013: Perinne ja muuttuvat nimet. Helsingin ortodoksisessa seurakunnassa vuosina 2000-2009 kastettujen lasten ensinimet. Suomen kielen pro gradu -tutkielma. Helsingin yliopisto.

Jä RVINEN, HARMA 2001: Isoisältä pojalle, isoäidiltä tyttärelle. Suvun nimien antaminen ja nimenmääräytymistapa esikristilliseltä ajalta nykypäiviin. Etnologian lisensiaatin tutkielma. Jyväskylän yliopisto.

Kiviniemi, Eero 1982: Rakkaan lapsen monet nimet. Suomalaisten etunimet ja 
nimenvalinta. Espoo: Weilin + Göös.

- 2006: Suomalaisten etunimet. Helsinki: Suomalaisen Kirjallisuuden Seura.

Kohlheim, Rosa - Kohlheim, Volker 2013: Duden - Lexikon der Vornamen. Mannheim: Dudenverlag.

Kolehmainen, TARU 2014: Kielenhuollon juurilla. Suomen kielen ohjailun historiaa. Helsinki: Suomalaisen Kirjallisuuden Seura ja Kotimaisten kielten keskus.

Kotilainen, Sofia 2008: Suvun nimissä. Nimenannon käytännöt Sisä-Suomessa 170o-luvun alusta 1950-luvulle. Bibliotheca Historica 120. Helsinki: Suomalaisen Kirjallisuuden Seura.

Lampinen, ArJa 1997: Ristimänimien valinta ja nimenannon uudennokset Jyväskylässä 1766-1930. Suomen kielen lisensiaatintutkielma. Turun yliopisto.

Lappalainen, Ritt ta 1996: Henricistä Anna Maria Seraphinaan. 170o- ja 180o-luvun kuopiolaisten etunimistä. Suomen kielen pro gradu -tutkielma. Joensuun yliopisto.

Mikkonen, Pirjo (toim.) 2002: Sukunimi? Etunimi? Maahanmuuttajien nimijärjestelmistä. Kielenkäytön oppaita 3. Helsinki: Kotimaisten kielten tutkimuskeskus.

Oksanen, Reetta 2007: "Se nimen määrää kenen lapsi on”. Sukujen etunimistä ja nimeämismalleista Pohjois-Savossa ja Pohjanmaalla 17oo-luvun alusta 19oo-luvun alkuun. Suomen historian pro gradu -tutkielma. Joensuun yliopisto.

PAikKAla, Sirkka 2006: Aamu Rusko ja Pylwäs Wankka. Etunimikeskustelua 18oo-luvun jälkipuoliskolta. - Taru Nordlund, Tiina Onikki-Rantajääskö \& Toni Suutari (toim.), Kohtauspaikkana kieli. Näkökulmia persoonaan, muutoksiin ja valintoihin s. 314-339. Helsinki: Suomalaisen Kirjallisuuden Seura.

Patronen, Outi 2017: Rajakarjalaisen sukunimistön kehittyminen osana Suomen karjalankielisen ortodoksivähemmistön suomalaistumista 1818-1925. Helsinki: Suomalaisen Kirjallisuuden Seura.

Rajasuu, Rirtta 2013: Kuopiossa, Oulussa ja Turussa vuosina 1725-1744 ja 18251844 syntyneiden kastenimet. Joensuu: Itä-Suomen yliopisto.

SArtjärvi, Maija 2011: Aija ja Meija, Anja ja Minja. Kaksitavuisten ija- ja njapäätteisten naistennimien yleistyminen ja suosionvaihtelu. Suomen kielen pro gradu -tutkielma. Helsingin yliopisto.

Seibicke, Wilfried 1996: Historisches Deutsches Vornamenbuch. Band 1. A-E. Berlin: Walter de Gruyter.

Tokola, JAANA 1997: Etunimi - merkki yhteisöllisyydestä vai yksilöllisyydestä? Etunimi maalaisväestön maailmankuvan ja perhekäsityksen heijastajana 180o-luvun Kalajoella. Suomen historian pro gradu -tutkielma. Jyväskylän yliopisto.

Turunen, Irene 1996: Enolaiset etunimet. Evankelisluterilaisen seurakunnan ristimänimistö v. 1780-1994. Suomen kielen pro gradu -tutkielma. Joensuun yliopisto. 